\title{
Taxonomy and Uncertainties of Cloud Manufacturing
}

\author{
Yaser Yadekar, Essam Shehab*, Jörn Mehnen \\ Manufacturing Department, School of Aerospace, Transport and Manufacturing, Cranfield \\ University, Cranfield, MK43 OAL, UK
}

\begin{abstract}
The manufacturing industry is currently undergoing rapid changes because of the rapid growth of advanced technologies in information systems and networks, which allow for collaboration around the world. This combination of the latest information technologies and advanced manufacturing networks has led to the growth of a new manufacturing model known as Cloud Manufacturing. Because Cloud Manufacturing is considered an emerging research area, there are significant gaps in the literature regarding the concept of Cloud Manufacturing, its implementation, and in particular the uncertainties coming with this new technology. This research aims to explain the concept of Cloud Manufacturing, its capabilities and potential. This work also introduces Cloud Manufacturing taxonomy, and investigates uncertainties that come with employing Cloud Manufacturing. Finally, proposals for future research in the context of Cloud Manufacturing are presented to address opportunities in Cloud Manufacturing.
\end{abstract}

Keywords: Cloud Manufacturing, Taxonomy, Uncertainty

\section{Introduction}

From craft production to agile manufacturing, manufacturing has become an ever more complex process, relying on many new technologies and advanced networks in response to changes in local, national, and international markets (Wang et al., 2012; Valilai and Houshmand, 2013). Enterprises are trying to gain competitive advantage in global markets by using the latest technologies, along with advanced networks, to create collaboration (Huang et al., 2013; Zhang et al., 2014; Wang et al., 2014).

Although manufacturers benefit from the implementation of state-of-the-art network technologies in gaining advantage over competitors, there are problems in these existing network technologies that affect production within the manufacturing 
industry. Some of these problems include: the sharing of manufacturing resources, where the resources are centralised into the network but cannot be distributed through the network due to lack of manufacturing services management in the network; the inability to access the manufacturing hard resources (equipment) in the manufacturing network due to complications in transferring hard resources into the network (Laili et al., 2012; Xu, 2012; Gao et al., 2013); difficulty of knowledge sharing between manufacturing units, suppliers, customers, and partners due to geographical dimension, countries' regulations, different operation systems, and the amount of data and complex processes in manufacturing (Valilai and Houshmand, 2013).

To address these problems in the manufacturing industry, a new manufacturing model combines innovative technologies and existing manufacturing networks that have emerged to create a new concept called "Cloud Manufacturing" (Li and Mehnen, 2013). This model can provide and share manufacturing resources and manufacturing capabilities as services to the users in business (Laili et al., 2012).

The Cloud Manufacturing model is complex and involves many advanced technologies and networks that need to be integrated efficiently (Luo et al., 2013), and it provides the ability to exchange data and share knowledge among the different users across different enterprises and regions (Ren et al., 2014).

The uptake of the new manufacturing paradigms, such as Cloud Manufacturing, has so far been limited by industry that is as yet hesitant, due to a lack of understanding of all aspects of Cloud Manufacturing and its related uncertainties. A survey of the literature shows that majority of published papers focus only on Cloud Manufacturing architecture and the enabling technologies. There is an absence of other research issues, such as: understanding the Cloud Manufacturing concept, its implementation, its stakeholders' interactions and their activities, and in particular the uncertainties coming with this new technology.

This paper intends to introduce a taxonomy that can provide a description and classification of all aspects of Cloud Manufacturing in a well-organised structure. It will also identify all related uncertainties that exist in Cloud Manufacturing. The taxonomy and identified uncertainties can help both researchers and professionals to design, operate and implement Cloud Manufacturing, in order to fully utilise its benefits. 
The remainder of this paper is structured as follows: Section 2 provides a brief description of Cloud Manufacturing and uncertainties; Section 3 explains proposed methodology in this paper; Section 4 presents taxonomy for Cloud Manufacturing; Section 5 identifies uncertainty factors that categorised into three categories; Section 6 concludes the paper and discusses future work.

\section{Related Work}

\subsection{Cloud Manufacturing}

The use of new technologies and networks are becoming critical success factors in any enterprise (Yadekar et al., 2013). Today, the emergence of new technologies such as Cloud Computing, Internet of Things, Virtualisation, and Web Services, with the help of existing advanced manufacturing networks, can shift the manufacturing industry from production-oriented manufacturing to services-oriented manufacturing (Xu, 2012). The combination of innovative technologies and existing manufacturing networks has created a new concept, called "Cloud Manufacturing".

The fact that Cloud Manufacturing is considered as an emerging concept and living idea, which has not yet settled, means that there is currently a variety of definitions for Cloud Manufacturing in the literature (Tao et al., 2011a; Xu, 2012; Laili et al., 2012; Gao et al., 2013; Wang 2013; Huang et al., 2013; Wu et al., 2013). For example, Wang (2013) defines Cloud Manufacturing as "a new-generation serviceoriented approach to supporting multiple companies to deploy and manage services for manufacturing operations over the Internet".

From the variety of definitions, Cloud Manufacturing can be described as a manufacturing model that provides manufacturing resources and capabilities, and a knowledge base platform for collaboration between different users (consumers, manufacturers, suppliers) to achieve their goals by using the latest information technologies and advanced communications networks.

With an increase in research on Cloud Manufacturing, many scholars have presented architecture for Cloud Manufacturing. Many of the proposed architectures have similar layers and complexity structure, but a different number of layers. Yan et al., (2013) propose a framework of capability services management system for manufacturing equipment. While Xu (2012), illustrates four layers of a Cloud Manufacturing system framework: manufacturing resource layer that involves all the 
manufacturing resources and manufacturing capabilities required in the product development life cycle; manufacturing virtual service layer that involves identification and virtualization of manufacturing resources and the packaging of them as cloud manufacturing services; global service layer that manages these virtualized and encapsulated manufacturing resources and capabilities; and application layer that provides Cloud Manufacturing services to the users.

Wang and Xu (2013) suggest a detailed service-oriented Cloud Manufacturing system named Interoperable Cloud-based Manufacturing System (ICMS) with three layers architecture: Smart Cloud Manager (SCM), User Cloud (UCloud), and Manufacturing Cloud (MCloud). Wang (2013) proposes an Internet and Web-based service oriented system for dealing with the dynamic manufacturing processes within a Cloud Manufacturing environment. This proposed system design is for machine availability monitoring and process planning, which can improve system performance on the shop floor.

Globalisation, advanced communication networks and new technologies have allowed a small number of new established companies to implement some form of Cloud Manufacturing system in their business. 3D Creation Lab and Shapeways are examples of those companies that use a Cloud Manufacturing system to provide 3D printing services online (3D Creation Lab, 2013; Shapeways, 2013). The idea is to allow individuals to become members in their platform, where they can share ideas, create customised products and gain access to 3D printing technology. The first step in the process is to design the product by using any design software tool. Next, the design file is uploaded to company's platform. Then, the system calculates the total cost of this product and the member orders and pays for the service. Next, the printing facility begins to prepare and print the product. Finally, the product ships to the member.

PhotoBox is specialized in digital photo services. Their online services include photo printing, creating Photo books, cards, printed t-shirts, wall decor, photo mugs, personalised mobile phone cases and more (PhotoBox, 2013). First, the customer needs to upload their photos into PhotoBox's platform and select what type service that required. Next, the platform allows the customer to be part of the design process by choosing type, shape and color of the product. Finally, the customer pays and then receives the product through the mail. 
Quirky, a small in-house manufacturing enterprise, is another example of Cloud Manufacturing (Quirky, 2013). The process followed by the company consists of several steps: an individual submits an idea to Quirky; Quirky presents this idea to a group of industry experts, friends and community members to decide whether to manufacture this idea or not; if Quirky agrees to manufacture this idea, the individual and community members become part of design process; finally, an agreed upon product is manufactured by Quirky, who then sell it through their website and other retailers.

\subsection{Uncertainty}

The world is undergoing rapid transformation and becoming a more complex environment as a result of new technologies and advanced communication, new innovations and globalization (Yadekar et al., 2014b). These changes lead to new situations that are unknown and unpredictable and they produce doubt though a lack of assurance and confidence. These situations are as a result of uncertainties and risks that need to be understood and dealt with in the real world. Uncertainties can influence the decision-making process (Erkoyuncu et al., 2013). The ability to understand and manage uncertainty and risk can enhance the decision-making process and allow enterprises to gain competitive advantage.

Today, there is still controversy amongst scholars about the actual meanings of uncertainty and risk. According to Samson et al., (2009), the various definitions of uncertainty and risk that exist in literature depend on the problem itself, where every discipline has its own definitions. Although many scholars believe that uncertainty and risk are one concept, some researchers and decision makers like to distinguish between uncertainty and risk. Erkoyuncu et al., (2011) illustrate the difference between risk and uncertainty characteristics, as shown in Table (1):

Table 1 Distinction between uncertainty and risk (Erkoyuncu et al., 2011)

\begin{tabular}{lcc}
\hline \hline Characteristics & Uncertainty & Risk \\
\hline Outcome predictability & No & Yes (probabilistic) \\
Negative outcome (threat) & Yes & Yes \\
Positive outcome (opportunity) & Yes & No \\
Examples & service availability & bandwidth cost \\
\hline \hline
\end{tabular}


The following definitions of uncertainty and risk are considered the most appropriate for this research:

Uncertainty is "the lack of complete certainty, that is, the existence of more than one possibility. The "true" outcome/state/result/value is not known" (Hubbard, 2014). Risk is "a state of uncertainty where some of the possibilities involve a loss, catastrophe, or other undesirable outcome" (Hubbard, 2014).

\section{$3 \quad$ Research Methodology}

This paper addresses the questions of what are the requirements for Cloud Manufacturing and its types, characteristics and attributes, and what are the main uncertainty factors in Cloud Manufacturing. Thus, a combination of literature review, reports and documents, interviews, a questionnaire and meetings and workshops were used to collected and analyse data. Figure (1) shows the research methodology.

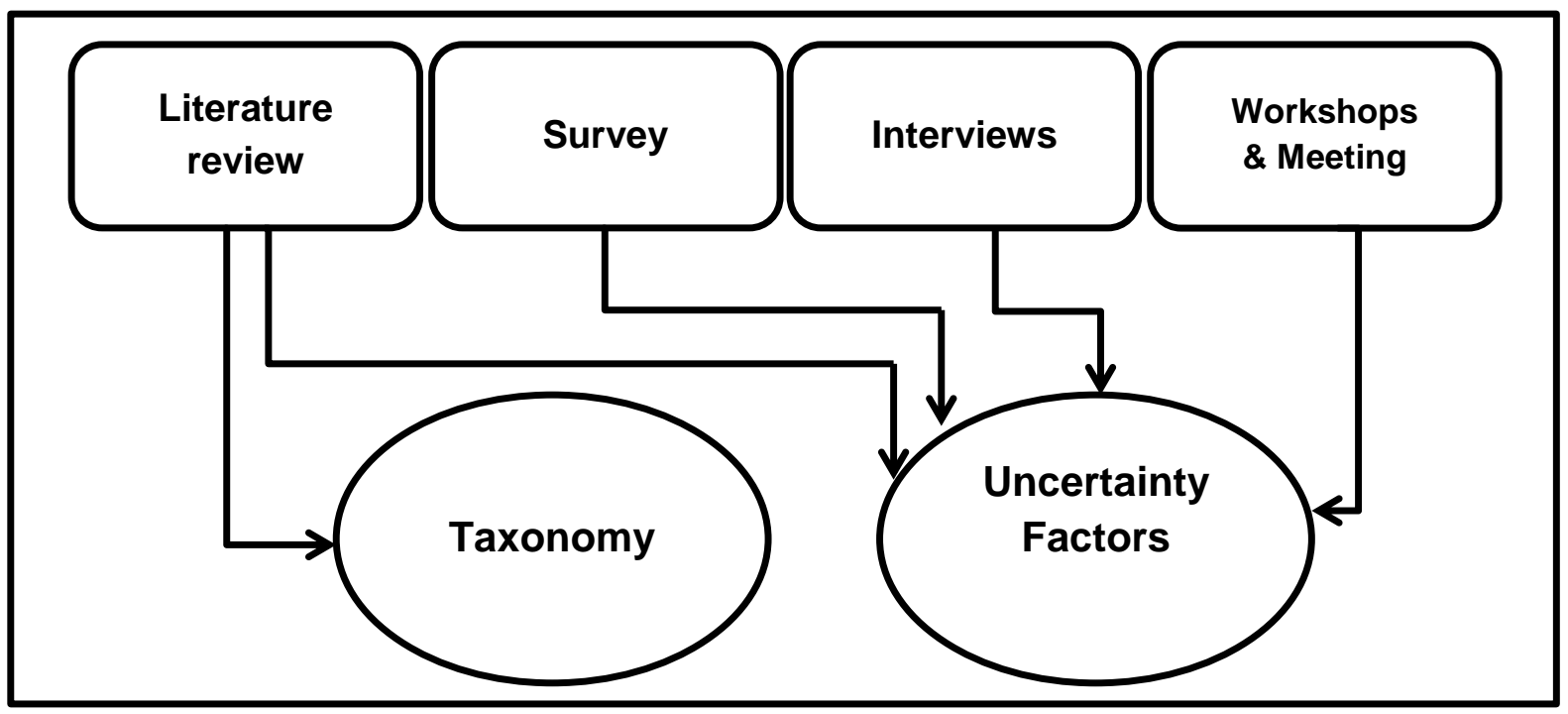

Fig. 1 Overview of research methodology

An extensive literature review was conducted to capture the challenges of Cloud technology in Manufacturing. The focus of this method was on literature related to Cloud technology implementation in Manufacturing and its challenges. In order to identify publications related to Cloud technology in Manufacturing, a search in both academic databases and search engines was conducted and limited to specific keywords: Cloud Computing, Cloud Manufacturing, Cloud technologies, Cloud risks, Cloud uncertainty, Cloud security, and Manufacturing. 
A questionnaire with a mix of open-ended, closed, and scale questions was designed. This was based on the literature review, participation in online group discussions (Linkedln) and interviews. The aim of this questionnaire was to: capture requirements for those using or considering adopting Cloud Computing technology in their enterprises; measure the awareness of Cloud Computing technology between individuals and enterprises; and identify challenges of Cloud Computing technology in the manufacturing environment.

The pilot questionnaire was distributed to a sample of four individuals (two experts and two researchers) to check wording, codes of closed questions, and questionnaire instructions. The feedback from the pilot questionnaire resulted in adding multiple choice answers for two questions. The final design of the questionnaire includes two sections with a total of 13 questions. The first section shows the characteristics of the respondent and their organization. The second section concentrates on the use or adopting of Cloud Technology in the respondent's organisation.

The questionnaire was designed by using Cranfield University's Qualtrics survey tool to design the survey instrument, and distributed online via email. The email included an invitation to participate in this online survey, an explanation of its aims, a questionnaire link, approximate time to complete the questionnaire, and time frame of the questionnaire (which was one month).

A set of interviews in both academia and industry were conducted to understand problems and challenges in Cloud Manufacturing. Interviews involved face-to-face and online meetings, or were conducted by email. In academia, active researchers in the Cloud Manufacturing research field were sourced using the online academic search engines. The active researchers were asked to elicit their thoughts and opinions on the potential uncertainties in Cloud Manufacturing. In industry, interactions were made with members of the CAPP-4-SMEs project, which is supported by the European Union's Seventh Framework Programme. The interactions required the author to conduct interviews, participate in weekly online meeting, and attend workshops.

Additionally, gathering information from well-known organisations that are interested in Cloud Computing technology as well as using documents available to the public from companies' websites, was an important source of data collection. 


\section{Cloud Manufacturing Taxonomy}

Capturing requirements for Cloud Manufacturing and its types, characteristics and attributes in the form of taxonomy can allow enterprises to understand and choose a suitable Cloud Manufacturing system. Taxonomy of Cloud Manufacturing is presented after conducting a comprehensive review of Cloud Manufacturing literature (as mentioned in Section 3). This taxonomy provides a classification of Cloud Manufacturing into six main areas, where the distinguishing attributes are listed under each main area, as shown in Figure (2).

\subsection{Cloud Manufacturing deployment models}

There are four types of deployment models in the Cloud environment: public Cloud, private Cloud, community Cloud and hybrid Cloud (Marston et al., 2011; Tao et al., 2011; Xu, 2012). Each type is designed for a specific situation suitable for the particular enterprise and has its own requirements. Cloud Manufacturing can use any of four types of deployment models in its architecture to transfer manufacturing resources and capabilities into the Cloud Manufacturing.

A public Cloud offers services and infrastructure from an off-site, third party service provider via the Internet. All operations in the Cloud system (provisioning, maintenance, management, installation, and update) are the service provider's responsibilities. Customers in this deployment model are charged only for service according to their needs. In addition, Cloud services are used and shared among different users. The advantage of this kind of Cloud is in reducing the cost of (IT) solutions in the enterprise. However, security and privacy issues are the disadvantages of this type of the deployment model. An example of a public Cloud is MFG.com, a marketplace for both buyers who are looking for resources or capability for their product and suppliers that provide material or services. 


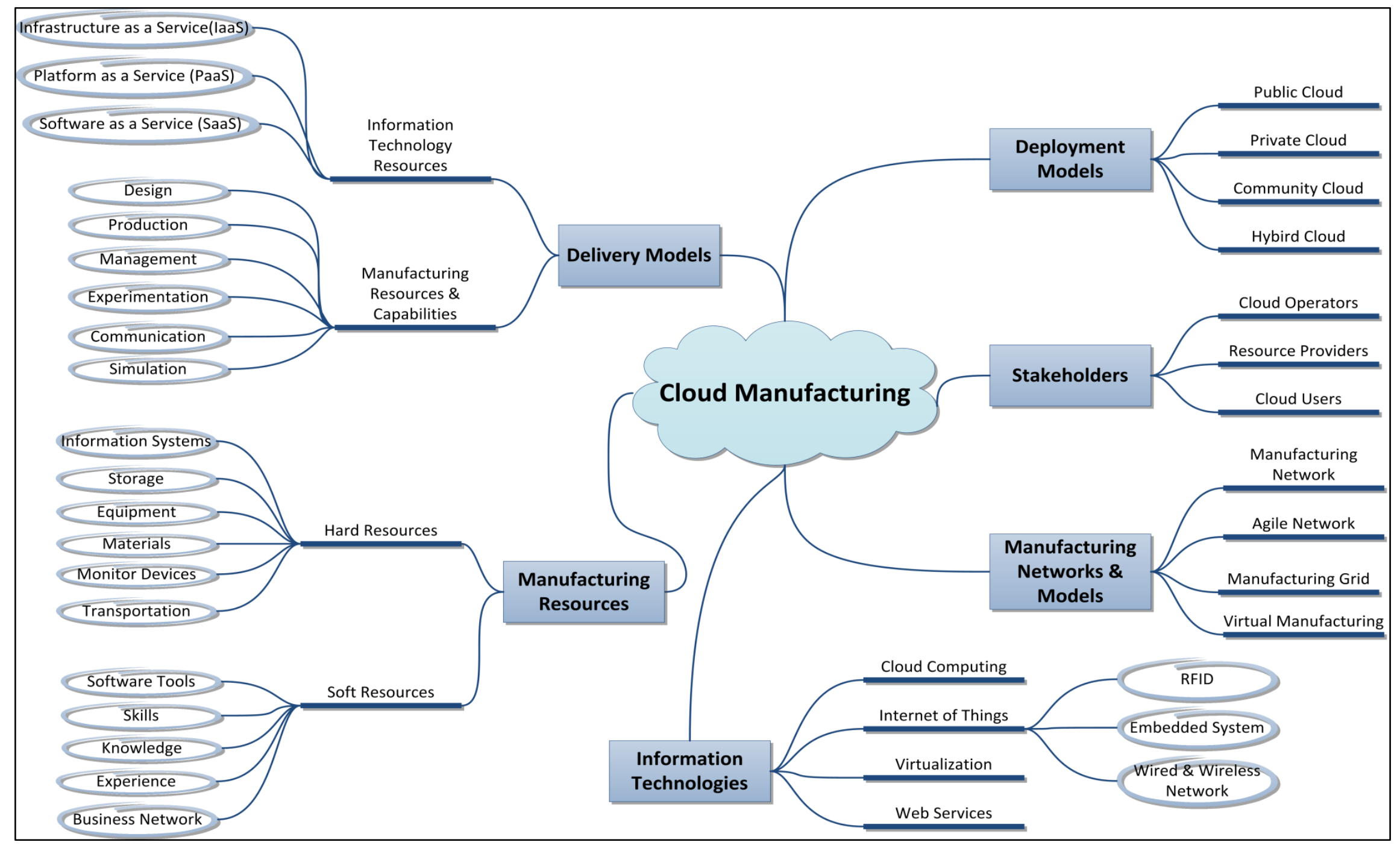

Fig. 2 Cloud Manufacturing Taxonomy 
A private Cloud provides an enterprise with the same services and infrastructure as the public Cloud, but is managed internally, with only the one organization using the Cloud services. The key advantage of this Cloud is the ability to control the Cloud infrastructure without third party intervention. Access for the private Coud is also limited to the organization's users only. Organisations often prefer using a private Cloud for critical data and applications. The major downside of the private Cloud is the cost. Building and operating a private Cloud can be a costly option for organisations, especially SMEs due to up-front capital costs and investments related to private Cloud infrastructure (Zhang et al., 2010).

A community Cloud is used and supported by several organizations that have the mutual interests and concerns. For example in United Kingdom, the National Health Service (NHS) has begun a pilot scheme to store healthcare data from different sources into the Cloud. This scheme will allow patients to share their personal information with General Practitioners (GP) and consultants (Cloud Industry Forum, 2014).

While a hybrid Cloud consists of two types of Cloud, a public Cloud and a private Cloud. This Cloud is used by enterprises to determine how to distribute and share critical information, services and infrastructure within or outside the enterprise. Noncritical data is migrated into a public Cloud whereas critical data is migrated into a private Cloud (Marston et al., 2011). This Cloud provides control for organisations to share their data and applications at different levels of access with others (consumers, suppliers, and partners).

\subsection{Cloud Manufacturing delivery models}

There are two classifications of service delivery models in Cloud Manufacturing: the first type depends on the information technology resources (storage, software, server, and network); whereas the second type depends on manufacturing resources and capabilities (design, production, quality control, simulation, transportation, and experimentation) (Wang and $\mathrm{Xu}, 2013$; Wu, 2013).

The information technology resources type includes three service delivery models: Infrastructure as a Service (laaS), Platform as a Service (PaaS), and Software as a Service (SaaS) (Furht, 2010; Yang et al., 2012). In laaS, all hardware (server, storage 
space, and networking components) that are needed to support all computational operations in the enterprise are owned and controlled by Cloud providers. They deliver this service to the enterprise based on enterprise's requirements. PaaS provides the computing platform, which includes the operating system, programming language, and database, to the enterprise as a service. This platform allows developers to create their own software applications by using tools supplied by Cloud provider. The SaaS service delivery model provides software applications to the users without the need to purchase, install and maintain the application, where the application is run through the Internet from the Cloud (Sudha and Viswanatham, 2013).

The other type includes all the manufacturing resources and capabilities involved in aspects of manufacturing can be delivered via a service model for Cloud Manufacturing users. The service delivery models can be for example, design, production, or communication as services in Cloud Manufacturing System. These delivery models may result from collaboration among different enterprises (Wang and $\mathrm{Xu}, 2013$ ).

\subsection{Cloud Manufacturing stakeholders}

The main stakeholders in any typical information system environment are providers who sell, install, license, maintenance the system; and consumers who use, own, maintain and upgrade the system (Marston et al., 2011). However, in a Cloud environment, new stakeholders appear and the role of providers and consumers changes. Stakeholders in a Cloud Manufacturing can be categorised into three main groups: Cloud users, Cloud resource providers, and Cloud operators (Xu, 2012; Wang and $\mathrm{Xu}, 2013 ; \mathrm{Wu}, 2013)$.

There are two types of users in this category, end-users and enterprise users. Both types of users are considered as consumers or organisations subscribed to a service in the Cloud Manufacturing, and need to access manufacturing resources and/or manufacturing capabilities to conduct a production task.

Cloud resource providers are responsible for delivering manufacturing resources

and manufacturing capabilities to Cloud users. They own and operate manufacturing resources, such as manufacturing equipment, monitor control devices and materials. Also, they possess the experience and knowledge needed for the production process. 
The last main stakeholders are Cloud operators that own and manage Cloud Manufacturing, and they are responsible for delivering Cloud services to the users. They manage and control all activities in Cloud Manufacturing from system maintenance to adding/removing Cloud user account information; monitoring network communication and system performance.

\subsection{Cloud Manufacturing resources and capabilities}

Manufacturing resources can be divided into two groups: soft resources group, including software, knowledge, skill, experience, and business network; and hard resources group, comprising manufacturing equipment, monitor control devices, materials, transportation, storage, and computational resources (server, software, platform). Manufacturing capabilities refer to ability to transform manufacturing resource into another form (design, production, management, and communications) (Wang and $\mathrm{Xu}, 2013)$.

\subsection{Cloud Manufacturing Information Technologies}

Cloud Manufacturing is supported by four main information technologies: Cloud Computing, Internet of Things (IoT), virtualization and Web service. Besides Cloud Computing which mentioned earlier, Internet of Things (IoT) is the computing concept to connect physical objects and automatically exchange data over the Internet by using supporting technologies (Atzori et al., 2012). In other words, it is the ability to connect everyday devices (coffee maker, oven, smart phones, or machine tool) to the internet to interact with other devices. Elements of loT are: sensing (radio frequency identification), communication technologies (wireless sensors network, embedded system), and middleware (Gubbi et al., 2013). The radio frequency identification (RFID), which is used to identify tags attached to an object and transfer the data to the receiver wirelessly; wireless sensors network, which consists of distributed autonomous sensors used to monitor and for remote sensing of objects; and an embedded system, which is microprocessor system built into devices for specific functions and used to give realtime data. The Middleware is computer software that mediates communication between technological and application levels. 
Virtualisation is a computing approach to create a multiple virtual version of a single physical resource or capability, such as a server, storage device, network or even an operating system, to share it with other on the network (Bourguiba et al., 2012). It allows the sharing of resources among Cloud users, which results in the minimising of the cost of using physical resource or capability, for the users. Also, another benefit of virtualization is the ability to operate and support legacy systems that require old operation system, hardware, and software libraries (Wang et al., 2010).

With the evolution of communication networks and information technologies, a new technology has emerged, called "Web service". Web service is a software system that provides communication between different types of machines over the Internet without requiring human interaction (Kanwar et al., 2010). A major difference between Web services and websites is data interaction. Whereas in websites, humans interact with the website and access the data, in Web services, the data is accessed by software application. Web service components are: Extensible Markup Language (XML), which creates tags for the data; Standard Object Access Protocol (SOAP), which transfers the data; Universal Description, Discovery and Integration, which provides status of, services; and Web Services Definition Language (WSDL), which describes the services.

\subsection{Manufacturing networks and models}

Due to global competition and rapid growth of communication networks and information technology, many enterprises rely on a Manufacturing Network. This type of network allows manufacturing enterprises to communicate with suppliers and customers and exchange detailed data with them (Wiendahl and Lutz, 2002). Manufacturing Networks consist of original equipment manufacturer (OEM) plants, dealers, and suppliers which may be geographically dispersed (Mourtzis et al. 2013). The benefit of using a Manufacturing Network is the ability to integrate both large enterprises and SMEs characteristics together; for example, critical mass in large enterprises and niche markets in SMEs (Butala and Sluga, 2006).

Agile Manufacturing can be described as "the capability to survive and prosper in a competitive environment of continuous and unpredictable change by reacting quickly and effectively to changing markets, driven by customer-designed products and 
services" (Gunasekaran, 1998). This manufacturing model concentrates on customised products rather than mass production. It has the ability to respond to expected and unexpected changes in the market and customer demands (Panchal and Schaefer, 2007). Agile Manufacturing characteristics are: producing high quality customized products; providing products and services with high information and value-added content; mobilization of core competencies; interacting with social and environmental issues; installation of various technologies; and dealing with uncertainty (Yusuf et al., 1999).

The concept of a Manufacturing Grid is to combine different enterprises together in order to join their manufacturing resources that are distributed in heterogeneous systems and in multiple sites, into one manufacturing system (Tao et al., 2010). Manufacturing Grids depend on three main technologies (grid technologies, information technologies, computer and advanced management technologies) to offer access to the manufacturing services that are needed by the users. Distributed, dynamic, autonomous, and transparent manufacturing resources are the characteristics of a Manufacturing Grid (Tao et al., 2011b).

\subsection{Taxonomy validation}

To validate the taxonomy, an interview with two experts was conducted to capture their views after presenting the taxonomy. The following questions were posed to the experts:

1) Would the taxonomy be useful for researchers and for enterprises that using or considering adopting Cloud Manufacturing?

2) Are the concepts and terminology in the taxonomy well explained and easy to understand?

3) What are improvements are needed for the taxonomy?

The experts agreed that the taxonomy is well-organised and covers the main aspects of Cloud Manufacturing. The description and explanation are comprehensive and easy to understand. The experts' suggestion for improvement the taxonomy is to add real-life examples in each category of the taxonomy. 
Findings from this taxonomy can describe Cloud Manufacturing as a manufacturing model that provides a platform for collaborations between different users (consumers, manufacturers, suppliers) to achieve their goals by using the latest information technologies (Cloud Computing, IOT, Virtualisation, Web service) and advanced communications networks (Manufacturing Network, Agile Manufacturing, Manufacturing Grid). This model has three main stakeholders (Cloud users, Cloud resource providers, Cloud operators), and consists of four different deployment models (public Cloud, private Cloud, community Cloud, hybrid Cloud) and two delivery models.

\section{Uncertainty Factors}

In order to explore and capture uncertainties for Cloud manufacturing, a combination of literature review, reports and documents, interviews, questionnaire, and meetings and workshops with CAPP project members were used in this research (as mentioned in Section 3). A summary of 32 uncertainty factors have been identified and categorised into three categories. Tables (2), (3) and (4) show a detailed description for each uncertainty.

The selection of categories was based on categories in the related literature. The Data Security and Privacy category considers factors that result in a loss of confidentiality and integrity of a Cloud Manufacturing. The Technical category is defined as the failures associated with the technologies and services provided by Cloud Manufacturing. The Management category considers factors that affect the pricing in the Cloud and the ability to access, control and manage the Cloud.

\subsection{Data Security and Privacy Related Uncertainties}

Key uncertainties in Cloud Manufacturing are data security and privacy. Issues including data breach/control/location/leakage/transmission, insecure Cloud services interfaces, applications security, Cloud services interfaces development security, remote access, intellectual property (IP) protection, and encryption levels are the major concerns in terms of security and privacy in Cloud Manufacturing, and many enterprises do not want to adopt this technology because of these issues. Table (2) shows a detailed description of data security and privacy related uncertainties. 


\section{Table 2 Data security and privacy related uncertainties}

\begin{tabular}{|c|c|c|}
\hline No & Factor & Description \\
\hline 1 & Data Breach & $\begin{array}{l}\text { The uncertainty is related to data breach from } \\
\text { outside/inside users into the Cloud by hacking passwords } \\
\text { and key cracking and hosting malicious data. }\end{array}$ \\
\hline 2 & Data Control & $\begin{array}{l}\text { The uncertainty is related to loss of physical control over } \\
\text { data. }\end{array}$ \\
\hline 3 & Data Location & $\begin{array}{l}\text { The uncertainty is related to location of data that may } \\
\text { create conflict with regulations and data privacy laws in } \\
\text { company's country. }\end{array}$ \\
\hline 4 & $\begin{array}{l}\text { Data Loss or } \\
\text { Leakage }\end{array}$ & $\begin{array}{l}\text { The uncertainty is related to ability of deletion or alteration } \\
\text { of records without a backup, loss of an encoding key may } \\
\text { result in effective destruction, and unauthorized parties } \\
\text { must be prevented from gaining access to sensitive data. }\end{array}$ \\
\hline 5 & $\begin{array}{l}\text { Insecure Cloud } \\
\text { Services interfaces }\end{array}$ & $\begin{array}{l}\text { The uncertainty is related to anonymous access and/or } \\
\text { reusable tokens or passwords, clear-text authentication or } \\
\text { transmission of content, inflexible access controls or } \\
\text { improper authorizations, limited monitoring capabilities. }\end{array}$ \\
\hline 6 & Applications Security & $\begin{array}{l}\text { The uncertainty is related to ability of protecting software } \\
\text { applications from piracy, ip hacking, cloning security. }\end{array}$ \\
\hline 7 & $\begin{array}{l}\text { Cloud Services } \\
\text { interfaces data } \\
\text { transmission Security }\end{array}$ & $\begin{array}{l}\text { The uncertainty is related to transmission clean error and } \\
\text { message handling between Cloud services interfaces. }\end{array}$ \\
\hline 8 & $\begin{array}{l}\text { Cloud Services } \\
\text { interfaces } \\
\text { development Security }\end{array}$ & $\begin{array}{l}\text { The uncertainty is related to Cloud service interfaces } \\
\text { created by certain development tool chains like ASP.NET, } \\
\text { JAVA, can be insecure since not known security measures } \\
\text { that are used in the applications. }\end{array}$ \\
\hline 9 & $\begin{array}{l}\text { Remotely access } \\
\text { Cloud services } \\
\text { security }\end{array}$ & $\begin{array}{l}\text { The uncertainty is related to remotely access Cloud } \\
\text { services without effecting encryption/ decryption } \\
\text { mechanism in the Cloud. }\end{array}$ \\
\hline 10 & $\begin{array}{l}\text { Intellectual property } \\
\text { (IP) protection }\end{array}$ & $\begin{array}{l}\text { The uncertainty is related to ability of preventing } \\
\text { hacking/phishing attempts from competition. }\end{array}$ \\
\hline 11 & Encryption Levels & $\begin{array}{l}\text { The uncertainty is related to the ability to determine the } \\
\text { encryption type for each: data type, process, etc. }\end{array}$ \\
\hline
\end{tabular}


Lack in control of data and the problem that the location of the data in the Cloud might not be known may create conflicts with regulations and laws in an enterprise's country (Marston et al., 2011). In addition, private enterprise data that exists in an enterprise's premises might be accessible through Cloud services (Sudha and Viswanatham, 2013). An example of privacy concerns are in the European Union (Directive 1995) and the US, in that these regions have strict laws which prohibit moving certain types of data outside an enterprise's country.

A survey conducted in 2012 by Intel IT Centre showed that 87 percent of IT professionals from different countries (US, UK, Germany, China) were concerned about security issues in the public Clouds and 69 percent in the private Cloud. Also, the complexity of Cloud Manufacturing can create a fertile environment for security breaches with the losing of control of data and applications that are critical to the enterprise. In addition, if data is encrypted for a certain party (like user, company), the Cloud service that uses this data then needs to decrypt it. Therefore the Cloud needs to have the personal decryption key for that party. If the Cloud should encrypt the results again, it also needs the personal encryption key.

\subsection{Technical Related Uncertainties}

Due to the complexly of Cloud Manufacturing systems that involve the need for numerous advanced technologies and networks to be integrated efficiently, many technical uncertainties exist in the Cloud. Among these technical uncertainties are: scalability, bandwidth, Cloud service availability, machine availability, system integrity, data interoperability, hardware protection, latency, fault-tolerance, revision request, disaster recovery, and vendor lock-in.

Both manufacturing resources and manufacturing capabilities are core components of a Cloud Manufacturing system and many technologies (such as Internet of Things and wireless sensors) are needed to coordinate between the Cloud Manufacturing system and manufacturing process. But the amount of data collected from different equipment and tools can lead to overloading in the network, making data exchange very slow in the Manufacturing Cloud system. Also, more storage space could be needed in the Cloud due to data collection of real-time manufacturing 
resources, requiring more process resources from the Cloud to handle this data. All those issues can result in Cloud Manufacturing system failure. Table (3) shows detailed description of technical related uncertainties.

A number of incidents, such as the Gmail outage for three hours in 2009 and Salesforce service shutdown for six hours in 2008 (Sultan, 2011), can create doubts about Cloud capabilities for delivering critical data and applications for enterprises. The Cloud providers guarantee to deliver Cloud services to customers under any circumstances, but sometimes enterprises cannot access their data and Cloud resources due to network outage and system failures. The outage may be permanent, as a provider company has gone out of business, or temporary, as a result of failure in the provider company's systems (Kim et al., 2009). Either way, failure to provide data and Cloud resources can be a disaster for the enterprise, which cannot function without its data and Cloud resources.

The aim of Cloud Manufacturing is to share manufacturing resources and capabilities between different parties (manufacturing units, suppliers, other enterprises and customers). However, managing different information systems and different manufacturing systems under a Cloud Manufacturing umbrella can be a difficult task for both enterprises and Cloud providers. For example, legacy systems are substantial and irreplaceable in many enterprises and it is costly and time consuming to put them into the Cloud. Moreover, many Cloud systems' architectures are designed as closed, which prohibits interaction with other Cloud systems.

Also, different Cloud providers can create a vendor lock-in situation, where each Cloud provider has its own way of running the Cloud, which makes it difficult for enterprises to switch to other providers or to transfer data back to the enterprises' premises (Ogunde and Mehnen, 2013). This limits the choices for enterprises when choosing between other Cloud providers in the market or moving data and services between providers. 


\begin{tabular}{|c|c|c|}
\hline No & Factor & Description \\
\hline 1 & Scalability & 24 \\
\hline 2 & Bandwidth & $\begin{array}{l}\text { The uncertainty is related to ability of collect real-time data } \\
\text { from manufacturing resource to the server. This results in } \\
\text { huge demands on network bandwidth capability. }\end{array}$ \\
\hline 3 & $\begin{array}{l}\text { Cloud Service } \\
\text { Availability }\end{array}$ & $\begin{array}{l}\text { The uncertainty is related to network outage and system } \\
\text { failures OR Inability of access Cloud services due to lack of } \\
\text { network connectivity. }\end{array}$ \\
\hline 4 & $\begin{array}{l}\text { Hardware/Machine } \\
\text { Availability }\end{array}$ & $\begin{array}{l}\text { The uncertainty is related to hardware/machine availability } \\
\text { that multiple users are querying the same } \\
\text { hardware/machine parallel, how to guarantee the availability } \\
\text { and balance the work loads. }\end{array}$ \\
\hline 5 & System Integrity & $\begin{array}{l}\text { The uncertainty is related to ability to partition access rights } \\
\text { to each of stakeholders groups. }\end{array}$ \\
\hline 6 & $\begin{array}{l}\text { Data } \\
\text { Interoperability } \\
\text { /Standardization }\end{array}$ & $\begin{array}{l}\text { The uncertainty is related to ability to deal with different } \\
\text { CAD formats on the market may or may not be readable to } \\
\text { the Cloud. }\end{array}$ \\
\hline 7 & $\begin{array}{l}\text { Hardware } \\
\text { protection }\end{array}$ & $\begin{array}{l}\text { The uncertainty is related to ability of protecting } \\
\text { manufacturing physical resources, e.g. machines, robots. }\end{array}$ \\
\hline 8 & Latency & $\begin{array}{l}\text { The uncertainty is related time delay that Cloud service } \\
\text { experiences when processing requests. }\end{array}$ \\
\hline 9 & Fault-tolerance & $\begin{array}{l}\text { The uncertainty is related to the ability of a system to } \\
\text { continue to operate in the event of the failure of some of its } \\
\text { components. }\end{array}$ \\
\hline 10 & Revision Request & $\begin{array}{l}\text { The uncertainty is related to ability of design/manufacturing } \\
\text { request needs to be changed, according to the service } \\
\text { provider. How to process and who is responsible. }\end{array}$ \\
\hline 11 & Disaster Recovery & $\begin{array}{l}\text { The uncertainty is related to ability of recovering Cloud } \\
\text { services after a natural disaster, hardware theft, and } \\
\text { electronic mishaps. }\end{array}$ \\
\hline 12 & Vender-Lock in & $\begin{array}{l}\text { The uncertainty is related to Inability of a customer to move } \\
\text { their data and/or programs away from a Cloud computing } \\
\text { service provider. }\end{array}$ \\
\hline
\end{tabular}




\subsection{Management Related Uncertainties}

Availability, performance, security, reliability, and quality are the major concerns when enterprises use Cloud services. The relationship between Cloud providers and their customers needs to be more efficient and effective by using standards, agreements and regulations to make clear the responsibilities and duties of each party in a Cloud Manufacturing system. Table (4) shows a detailed description of management related uncertainties.

The Cloud providers need to reassure their customers about their services by using Service Level Agreements (SLA) (Xu 2012). Also, SLA can allow more transparency into the Cloud by providing standards between Cloud provider and their clients to reveal what is happening in the Cloud (Ramgovind et al., 2010). Although there is currently no official standard for Cloud Computing Technology, in 2011 the Cloud Security Alliance (CSA) announced that there is to be ongoing development of Cloud security and privacy standards in collaboration with International Organization for Standardization (ISO) and International Electrotechnical Commission (IEC). The standard is expected to be a guideline or code of practice for Cloud Computing Technology.

From an economic perspective, the purpose of using Cloud Manufacturing is to reduce the cost of using manufacturing services for the whole lifecycle of manufacturing (Tao et al., 2011a). Cloud Technology allows enterprises, especially SMEs, to use computing resources and capabilities at low cost. Research conducted by Hosseini et al., (2010), indicates that the implementation of Cloud technology in an enterprise over five years can have financial benefits that cost $37 \%$ less than traditional systems.

The implementation of Cloud Manufacturing can, however, raise costs due to issues regarding using network communication (bandwidth) to send and receive data from the Cloud. Costs can increase with changing Cloud monthly service fees, due to access to new technology and the need to consume more Cloud resources. There are also the issues of software application support stopping from the vendor, and the cost of moving data and workloads into Cloud. Using Cloud Manufacturing for large enterprises can be costly due to the need for more Cloud resources for their large projects (Ogunde 
and Mehnen 2013). There is an additional need for consumption management to trace all activities to calculate the consumption for each user in the Cloud (Xu, 2012).

\section{Table 4 Management related uncertainties}

\begin{tabular}{|c|c|c|}
\hline No & Factor & Description \\
\hline 1 & $\begin{array}{l}\text { Authentication } \\
\text { Mechanism }\end{array}$ & $\begin{array}{l}\text { The uncertainty is related to secure authentication methods to } \\
\text { access Cloud services. }\end{array}$ \\
\hline 2 & $\begin{array}{l}\text { Administrative } \\
\text { Management }\end{array}$ & $\begin{array}{l}\text { The uncertainty is related to administrative controls specifying } \\
\text { who can perform data related operations such as creation, } \\
\text { access, disclosure, transport, and destruction. }\end{array}$ \\
\hline 3 & $\begin{array}{l}\text { Permission } \\
\text { control }\end{array}$ & $\begin{array}{l}\text { The uncertainty is related to Permission to share manufacturing } \\
\text { resources, different users access to different resources. Need a } \\
\text { strategy to confirm the resource access to different levels of } \\
\text { users. }\end{array}$ \\
\hline 4 & User Boundary & $\begin{array}{l}\text { The uncertainty is related to how much data/resource the user is } \\
\text { able to access. How to protect the resource from unwanted } \\
\text { affects/operations from others. }\end{array}$ \\
\hline 5 & $\begin{array}{l}\text { Quality control } \\
\text { and assurance }\end{array}$ & $\begin{array}{l}\text { The uncertainty is related to monitor and document quality of } \\
\text { services provided through Cloud. Quality in terms of, for } \\
\text { example, accuracy, precision, reliability, etc. }\end{array}$ \\
\hline 6 & Training & The uncertainty is related to training staff for Cloud services. \\
\hline 7 & Standards & $\begin{array}{l}\text { The uncertainty is related to standards for interoperability } \\
\text { between Cloud services and in-house infrastructure, and need } \\
\text { to understand responsibilities of each party in the Cloud }\end{array}$ \\
\hline 8 & $\begin{array}{l}\text { Unexpected } \\
\text { cost/price } \\
\text { changing }\end{array}$ & $\begin{array}{l}\text { The uncertainty is related to how be the Cloud service are } \\
\text { priced. What if the cost of service is changed in the middle of } \\
\text { service. }\end{array}$ \\
\hline 9 & $\begin{array}{c}\text { Quality of } \\
\text { Service (QoS) }\end{array}$ & $\begin{array}{l}\text { The uncertainty is related to ability of providing a guarantee of } \\
\text { performance, availability, security. Manufacturing resource or } \\
\text { service is changing along with time, as well as its manufacturing } \\
\text { resource or service request. }\end{array}$ \\
\hline
\end{tabular}




\subsection{Uncertainty factors validation}

Firstly, the uncertainty factors were presented to two experts with knowledge in Cloud Manufacturing and information technology. The two experts were asked to provide feedback by adding to/deleting/modifying each uncertainty factor. Additionally, the uncertainty factors were presented to members of CAPP project followed by a group discussion. After interviews and group discussion, a finalised list of 32 uncertainty factors was created.

\section{Conclusions and Implication for Future Work}

The rapid growth of advanced technologies in information systems and networks has allowed the manufacturing industry to apply new, complex manufacturing systems based on advanced networks and new computing technologies. Cloud Manufacturing is one of these emerging technologies, and has a significant impact in the manufacturing industry by sharing manufacturing resources and capabilities as services, and creating collaboration. However, the transformation of existing manufacturing systems to new advanced and complex systems, such as Cloud Manufacturing, that incorporates many state-of-the-art technologies, can be a big challenge for any enterprise. It is vital to understand the Cloud Manufacturing concept, it capabilities and potentials, and role of uncertainties before embracing Cloud Manufacturing.

This paper indicates that the majority of scholars concentrate only on Cloud Manufacturing system architecture and the enabling technologies. In addition, there is a lack of understanding of the Cloud Manufacturing concept among researchers and enterprises. Finally, a number of uncertainties regarding data security and privacy, technical, and management in Cloud Manufacturing were presented in this paper.

For future work, there is a need to address more issues in the Cloud Manufacturing research area, such as: the lifecycle of Cloud Manufacturing; benefits of adopting Cloud Manufacturing; and the role and responsibility of stakeholders in a Cloud Manufacturing environment. There is also a requirement for standards for migrating into Cloud Manufacturing, and for interoperability between different Clouds and in-house infrastructures. Finally, there must be guidelines for enterprises to choose and develop secure Cloud Manufacturing systems. 


\section{Acknowledgments}

The authors would like to thank the CAPP-4-SMEs project members that is supported by EU 7th Framework Programme for their contributing to this paper. 


\section{Reference}

3D Creation Lab, About 3D Creation Lab, Retrieved on September 19, 2013 from 3D Creation Lab, http://www.3dcreationlab.co.uk/about 3d printing services.php

Abbadi, I., M. and Martin, A. (2011), "Trust in the Cloud ", Information Security Technical Report, vol. 16, no. 3, pp. 108-114.

Atzori, L., Iera, A., Morabito, G. and Nitti, M. (2012), "The Social Internet of Things (SloT) - When social networks meet the Internet of Things: Concept, architecture and network characterization", Computer Networks, vol. 56, no. 16, pp. 3594-3608.

Bourguiba, M., Haddadou, K. and Pujolle, G. (2012), "Packet aggregation based network I/O virtualization for cloud computing", Computer Communications, val. 35, no. 3, pp. 309-319.

Butala, P. and Sluga, A. (2006), "Autonomous Work Systems in Manufacturing Networks", CIRP Annals - Manufacturing Technology, vol. 55, no. 1, pp. 521-524.

Cloud Industry Forum, Retrieved on April 16, 2014 from http://cloudindustryforum.org/news/198-nhs-takes-first-step-to-storing-patientinformation-in-the-cloud

Cloud Security Alliance (CSA) (2010), Top Threats to Cloud Computing, Cloud Security Alliance.

Directive 95/46/EC of the European Parliament and of the Council of 24 October 1995 on the protection of individuals with regard to the processing of personal data and on the free movement of such data, Official Journal 281 (1995), pp. 31-50.

Erkoyuncu, J. A., Durugbo, C. and Roy, R. (2013), "Identifying uncertainties for industrial service delivery: a systems approach", International Journal of Production Research, [Online], pp. 6/09/2013-1-21 available at:

http://www.tandfonline.com/doi/full/10.1080/00207543.2013.794316\#.UIQplBCgtOI

Erkoyuncu, J. A., Roy, R., Shehab, E. and Cheruvu, K. (2011), "Understanding service uncertainties in industrial product-service system cost estimation", The International Journal of Advanced Manufacturing Technology, vol. 52, no. 9-12, pp. 1223-1238.

Furht, B. (2010), "Cloud Computing Fundamentals" in: Furht, B. and Escalante, A. (Eds.), Handbook of cloud computing, Springer, New York, pp. 3-19. 
Gao, X., Yang, M., Liu, Y. and Hou, X. (2013), "Conceptual model of multi-agent business collaboration based on cloud workflow", Journal of Theoretical and Applied Information Technology, vol. 48, no. 1, pp. 108-112.

Gubbi, J., Buyya, R., Marusic, S. and Palaniswami, M. (2013), "Internet of Things (loT): A vision, architectural elements, and future directions", Future Generation Computer Systems, vol. 29, no. 7, pp. 1645-1660.

Gunasekaran, A. (1998), "Agile manufacturing: enablers and an implementation framework", International Journal of Production Research, vol. 36, no. 5, pp. 12231247.

Haeberlen, T. and Dupré, L. (2012), "Cloud Computing: benefits, risks and recommendations for information security", European Union Agency for Network and Information Security (enisa), Greece.

Hogan, M., Liu, F., Sokol, A. and Tong, J. (2011), "Nist cloud computing standards roadmap", NIST Special Publication, pp. 35.

Huang, B., Li, C., Yin, C. and Zhao, X. (2013), "Cloud manufacturing service platform for small-and medium-sized enterprises", The International Journal of Advanced Manufacturing Technology, vol. 65, pp. 1261-1272.

Hubbard, D., W. (2014), How to Measure Anything: Finding the Value of "Intangibles" in Business, 3rd ed, John Wiley \& Sons, Inc., New Jersey, USA.

Intel IT Centre Survey (2012), "What's Holding Back the Cloud?”, Intel IT Centre.

Kanwar, R., U. Narayan, and V. Lakshmi. (2010), "Web service based hydrologic data distribution system”, Computers \& Geosciences, vol. 36, no. 7, pp. 819-826.

Khajeh-Hosseini, A., Greenwood, D., Smith, J. and Sommerville, I. (2010), "The cloud adoption toolkit: Addressing the challenges of cloud adoption in enterprise", Cornel University Library, [Online], available at: http://arxiv.org/abs/1003.3866.

Kim, W., Kim, S., Lee, E. and Lee, S. (2009), "Adoption issues for cloud computing", in: Proceedings-the $7^{\text {th }}$ International Conference on Advances in Mobile Computing and Multimedia, pp. 2-5.

Laili, Y., Tao, F., Zhang, L. and Sarker, B. R. (2012), "A study of optimal allocation of computing resources in cloud manufacturing systems", The International Journal of Advanced Manufacturing Technology, vol. 63, no. 5-8, pp. 671-690.

Li, W. and Mehnen J. (eds.) (2013), "Cloud Manufacturing Distributed Computing Technologies for Global and Sustainable Manufacturing”, Springer, London. 
Luo, Y., Zhang, L., Tao, F., Ren, L., Liu, Y., and Zhang, Z. (2013), "A modeling and description method of multidimensional information for manufacturing capability in cloud manufacturing system", The International Journal of Advanced Manufacturing Technology, vol. 69, no. 5-8, pp. 961-975.

Marston, S., Li, Z., Bandyopadhyay, S., Zhang, J. and Ghalsasi, A. (2011), "Cloud computing- The business perspective", Decision Support Systems, vol. 51, no. 1, pp. 176-189.

Mourtzis, D., Doukas, M. and Psarommatis, F. (2013), "Design and operation of manufacturing networks for mass customisation", CIRP Annals - Manufacturing Technology, vol. 62, no. 1, pp. 467-470.

Ogunde, N., A. and Mahnen, J. (2013), "Factors Affecting Cloud Technology Adoption: Potential User's Perspective", in Li, W. and Mahnen, J. (eds.) Cloud Manufacturing, Springer,

London, pp. 77-89.

Panchal, J. H. and Schaefer, D. (2007), "Towards achieving agility in web-based virtual enterprises: a decision-centric approach", International Journal of Internet Manufacturing and Services, vol. 1, no. 1, pp. 51-74.

PhotoBox, About Us, Retrieved on June 18, 2013 from PhotoBox, http://www.photobox.co.uk/content/about-us.

Quirky, Help How It Works, Retrieved on June 18, 2013 from Quirky, http://www.quirky.com/how-it-works.

Ramgovind, S., Eloff, M. and Smith, E. (2010), "The management of security in cloud computing", in: Proceedings-ISSA Conference on Information Security for South Africa, pp. 1-7.

Ren, L., Zhang, L., Wang, L., Tao, F. and Chai, X. (2014). "Cloud manufacturing: key characteristics and applications". International Journal of Computer Integrated Manufacturing, in press, pp. 1-15.

Samson, S., Reneke, J. A. and Wiecek, M. M. (2009), "A review of different perspectives on uncertainty and risk and an alternative modeling paradigm", Reliability Engineering \& System Safety, vol. 94, no. 2, pp. 558-567.

Shapeways, About Us, Retrieved on June 22, 2013 from Shapeways, http://www.shapeways.com/about?li=footer\#

Sudha, S. and Viswanatham, V. (2013), "Addressing security and privacy issues in Cloud Computing", Journal of Theoretical and Applied Information Technology, vol. 48, no. 2, pp. 708-719. 
Sultan, N., A. (2011), "Reaching for the "cloud": How SMEs can manage", International Journal of Information Management, vol. 31, no. 3, pp. 272 - 278.

Tao, F., Zhang, L., Venkatesh, V., Luo, Y. and Cheng, Y. (2011), "Cloud manufacturing: a computing and service-oriented manufacturing model", Proceedings of the Institution of Mechanical Engineers, Part B: Journal of Engineering Manufacture, vol. 225, no. 10, pp. 1969-1976.

Tao, F., Zhang, L. and Nee, A. Y. C. (2011), "A review of the application of grid technology in manufacturing", International Journal of Production Research, vol. 49, no. 13 , pp. 4119-4155.

Tao, F., Zhao, D., Yefa, H. and Zhou, Z. (2010), "Correlation-aware resource service composition and optimal-selection in manufacturing grid", European Journal of Operational Research, vol. 201, no. 1, pp. 129-143.

Valilai, O. F. and Houshmand, M. (2013), "A collaborative and integrated platform to support distributed manufacturing system using a service-oriented approach based on cloud computing paradigm", Robotics and Computer-Integrated Manufacturing, vol. 29, no. 1, pp. 110-127.

Wang, L. (2013), "Machine availability monitoring and machining process planning towards Cloud manufacturing", CIRP Journal of Manufacturing Science and Technology, vol. 6, no. 4, pp. 263-273.

Wang, S., Chen, G., Kang, L., and Li, Q. (2012). "Information model of cloud manufacturing resource based on semantic web" JDCTA: International Journal of Digital Content Technology and its Applications, vol. 6, no.19, pp.339-346.

Wang, S. L., Guo, L., Kang, L., Li, C. S., Li, X. Y. and Stephane, Y. M. (2014). "Research on selection strategy of machining equipment in cloud manufacturing", The International Journal of Advanced Manufacturing Technology, vol. 71, no. 9-12, pp.1549-1563.

Wang, X., V. and Xu, X. W. (2013), "An interoperable solution for Cloud manufacturing", Robotics and Computer-Integrated Manufacturing, vol. 29, no. 4, pp. 232-247.

Wiendahl, H. and Lutz, S. (2002), "Production in networks", CIRP AnnalsManufacturing Technology, vol. 51, no. 2, pp. 573-586.

Wu, D., Greer, M. J., Rosen, D. W. and Schaefer, D. (2013), "Cloud manufacturing: Strategic vision and state-of-the-art", Journal of Manufacturing Systems, vol. 32, no. 4, pp. 564-579.

Wyld, D. C. (2009), Moving to the cloud: An introduction to cloud computing in government, IBM Center for the Business of Government. 
$\mathrm{Xu}, \mathrm{X}$. (2012), "From cloud computing to cloud manufacturing", Robotics and Computer-Integrated Manufacturing, vol. 28, no. 1, pp. 75-86.

Yadekar, Y., E. Shehab, and J. Mehnen. (2013), Challenges of Cloud Technology in Manufacturing Environment. In Proceedings of the 11th International Conference on Manufacturing Research (ICMR 2013), Cranfield, pp. 177-182.

Yadekar Y, Shehab E and Mehnen J. (2014), "A Taxonomy for Cloud Manufacturing" In Proceedings of the 12th International Conference on Manufacturing Research (ICMR 2014), Southampton Solent University, Southampton UK, pp. 103-108.

Yadekar Y, Shehab E and Mehnen J. (2014), "Uncertainties in Cloud Manufacturing" In Proceedings of International Conference on Concurrent Engineering, China: EBook: Moving Integrated Product Development to Service Clouds in the Global Economy, vol. 1, pp. 297-305, ISBN 978-1-61499-440-4 (online).

Yan, J., Xin, S., Liu, Q. and Xu, W. (2013), "Capability Service Management System for Manufacturing Equipments in Cloud Manufacturing", Advances in information Sciences and Service Sciences, vol. 5, no. 5, pp. 677-685.

Yang, N., Li, D. and Tong, Y. (2012), "A cloud computing-based ERP system under the cloud manufacturing environment", International Journal of Digital Content Technology and its Applications, vol. 6, no. 23, pp. 126-134.

Yusuf, Y. Y., Sarhadi, M. and Gunasekaran, A. (1999), "Agile manufacturing: The drivers, concepts and attributes", International Journal of Production Economics, vol. 62, no. 1, pp. 33-43.

Zhang, L., Luo, Y., Tao, F., Li, B. H., Ren, L., Zhang, X. and Liu, Y. (2014). Cloud manufacturing: a new manufacturing paradigm. Enterprise Information Systems, vol. 8, no. 2, pp.167-187.

Zhang, Q., L. Cheng, and Boutaba, R. (2010), "Cloud computing: state-of-the-art and research challenges". Journal of internet services and applications, vol. 1, no. 1, pp.7-18. 